Article

\title{
Confirmation of ENSO-Southern Ocean Teleconnections Using Satellite-Derived SST
}

\author{
Brady S. Ferster ${ }^{1, *}$ (D), Bulusu Subrahmanyam ${ }^{1}$ (i) and Alison M. Macdonald ${ }^{2}$ \\ 1 School of the Earth, Ocean and Environment, University of South Carolina, 701 Sumter Street, \\ Columbia, SC 29208, USA; sbulusu@geol.sc.edu \\ 2 Physical Oceanography Department, Woods Hole Oceanographic Institution, MS 21, 266 Woods Hole Rd., \\ Woods Hole, MA 02543, USA; amacdonald@whoi.edu \\ * Correspondence: bferster@seoe.sc.edu; Tel.: +1-803-777-4529
}

Received: 26 January 2018; Accepted: 19 February 2018; Published: 23 February 2018

\begin{abstract}
The Southern Ocean is the focus of many physical, chemical, and biological analyses due to its global importance and highly variable climate. This analysis of sea surface temperatures (SST) and global teleconnections shows that SSTs are significantly spatially correlated with both the Antarctic Oscillation and the Southern Oscillation, with spatial correlations between the indices and standardized SST anomalies approaching 1.0. Here, we report that the recent positive patterns in the Antarctic and Southern Oscillations are driving negative (cooling) trends in SST in the high latitude Southern Ocean and positive (warming) trends within the Southern Hemisphere sub-tropics and mid-latitudes. The coefficient of regression over the 35-year period analyzed implies that standardized temperatures have warmed at a rate of 0.0142 per year between 1982 and 2016 with a monthly standard error in the regression of 0.0008 . Further regression calculations between the indices and SST indicate strong seasonality in response to changes in atmospheric circulation, with the strongest feedback occurring throughout the austral summer and autumn.
\end{abstract}

Keywords: Southern Ocean; sea surface temperature; teleconnections; Antarctic Oscillation; El Niño-Southern Oscillation; AVHRR

\section{Introduction}

Southern Ocean is a highly dynamic component of the global ocean circulation that plays a key role in the transport of heat, the uptake of carbon, and the global climate system [1-8]. The Southern Ocean circulation is largely wind driven. Changes in the Southern Hemisphere wind field drive sea surface temperature (SST) gradients that can support a feedback mechanism and influence both the latitude of the Antarctic Circumpolar Current (ACC) and the distributions of heat and nutrients [9-13]. Southern Hemisphere atmospheric variability exhibits a large number of modes, mostly influenced by large-scale low-frequency patterns [14] and has been known to play a major role in Southern Hemisphere weather and climate $[15,16]$. Due to the wave patterns associated with large-scale teleconnections, the largest temperature anomalies occur in the Amundsen-Bellingshausen Sea [17]. For a more in-depth analysis into the relationship between large-scale atmospheric teleconnections and Southern Ocean SST, refer to [17]. To analyze trends of Southern Hemisphere air-sea interactions, two patterns of atmospheric variability are compared with SST: the Antarctic Oscillation (AAO) and the Southern Oscillation (SO).

The AAO (also referred as the Southern Annular Mode) is a large-scale low-frequency pattern and is the dominant mode of atmospheric variability in the Southern Hemisphere Westerlies [16]. Previous studies found that the westerly winds have shifted south due to the increasing frequency of the AAO and the growing Antarctic ozone hole $[18,19]$ and significant changes have been observed in both the temperature and salinity of the Southern Ocean $[4,20,21]$. However, despite the increasing 
frequency of the $\mathrm{AAO}$ and the shifting Westerlies, statistical evidence indicates an insensitivity of the ACC and sloping isopycnals to decadal changes in wind stress [22]. Within the Southern Ocean and Antarctic waters, previous studies have compared SST with the AAO [23-25] on weekly to monthly scales, noting the significant anomalies induced by the atmospheric pattern.

The SO is a measure of the Walker circulation in the tropical South Pacific. This circulation relates to variations in ocean temperatures and atmospheric pressure across the broad expanse of the tropical Pacific. The SO is also a metric for the El Niño-Southern Oscillation (ENSO) index. Negative (positive) SO index signifies warm (cold) SST across the eastern tropical Pacific and can therefore describe patterns similar to El Niño (La Niña) events. Additionally, the SO and El Niño (La Niña) were found to be negatively (positively) related to the Pacific-South American (PSA) wave pattern [26], which can have strong influences on SST, sea-ice, and atmospheric temperatures along Antarctica [27-29]. Reference [29] describes the strengthened influence of the AAO and SO during in phase periods, indicating the strong relationship between the atmospheric circulation and the effect on ocean dynamics. In this analysis, the statistical significance of the influence of teleconnections on Southern Ocean SST is investigated.

Hypothesizing that the SO has a greater influence than the AAO in the Southern Ocean and that both teleconnections drive warming (cooling) trends during positive (negative) phases of the oscillations, this analysis compares atmospheric teleconnections to Southern Ocean SST in both space and time. Investigation of the relationships between SST patterns and atmospheric variability with which they are associated provides a basis for improved understanding of Antarctic sea-ice and air-sea dynamics within the Southern Ocean.

\section{Materials and Methods}

\subsection{Observational Data}

Historically, in situ observations in the Southern Ocean have been sparse and made difficult due to harsh austral winter conditions. Southern Ocean in situ observations were particularly limited prior to the Argo float program, with most of the high-quality collections derived from repeat hydrography programs [30,31], such as the World Ocean Circulation Experiment (WOCE). Compared to in situ observations, satellites have relatively high spatial resolution and for SST a long temporal record extending back to the 1980's. The Optimal Interpolated Sea Surface Temperatures version 2 (OISST v2) product [32], utilizes statistically blended Advanced Very High Resolution Radiometer (AVHRR) data and in situ measurements to accurately represent the sea surface. OISST v2 is obtained from the National Oceanic and Atmospheric Administration (NOAA) Earth Science Research Laboratory Physical Science Division. OISST v2 [32] has $0.25^{\circ}$ resolution spatially and temporal coverage dating back to September 1981. For this analysis, full-year only, high-resolution AVHRR data were used (1982-2016) to prevent seasonal bias, and all data points with satellite-derived fractional sea-ice in the high latitudes were removed.

Variability in SST anomalies is compared against proxies for large-scale, low frequency climate patterns of $\mathrm{AAO}$ and $\mathrm{SO}$. Both the $\mathrm{AAO}$ and $\mathrm{SO}$ indices come from the National Centers of Environmental Prediction, Climate Prediction Center (NCEP, CPC). AAO index is computed from the leading empirical orthogonal function of $700 \mathrm{hPa}$ height anomalies between mid- and high latitudes from NCEP/NCAR (National Center for Atmospheric Research) reanalysis data [33]. SO index is computed from standardized observed sea level pressure anomalies between Tahiti, French Polynesia and Darwin, Australia, divided by monthly standard deviations [34].

\subsection{Methods}

To analyze the teleconnections and standardized SST anomalies, multiple statistical tests are performed. To calculate standardized anomalies, the monthly mean climatology from OISST v2 (1982-2016) is subtracted from the monthly SST record and divided by the monthly standard deviation 
of OISST v2, effectively removing seasonality. Standardized anomalies typically provide a better representation on the magnitude of anomalies since the influences of dispersion have been removed. The linear regressions of standardized anomalies are calculated using whole years for the duration of OISST v2 SST, 1982-2016. Within the regressions and correlations, $p$-values are used to determine significance (alpha $=0.05$ ). Positive (negative) indices are defined as those above (below) the 70th (30th) percentile, which is approximately $0.5(-0.5)$. We define neutral years as those with indices between -0.5 and 0.5 . Additional seasonal comparisons define austral summer as January through March and austral winter as July through September.

\section{Results}

We begin by addressing the relationship between SST and the large-scale AAO and SO teleconnections during the period 1982-2016. This period is used as it includes all full years in the OISST v2 data product. As described above, to reduce seasonal bias, standardized anomalies are compared against the large-scale patterns of AAO and SO indices. Correlations between SST and the teleconnections (Figure 1a,b) relate positive anomalies in the mid-latitudes $\left(30^{\circ} \mathrm{S}-50^{\circ} \mathrm{S}\right)$ and negative anomalies in the high latitude regions during positive phases. A positive AAO is associated with a poleward shift in the Westerlies, while a positive SO describes anomalously cold temperatures in the eastern Pacific (similar to La Niña events).
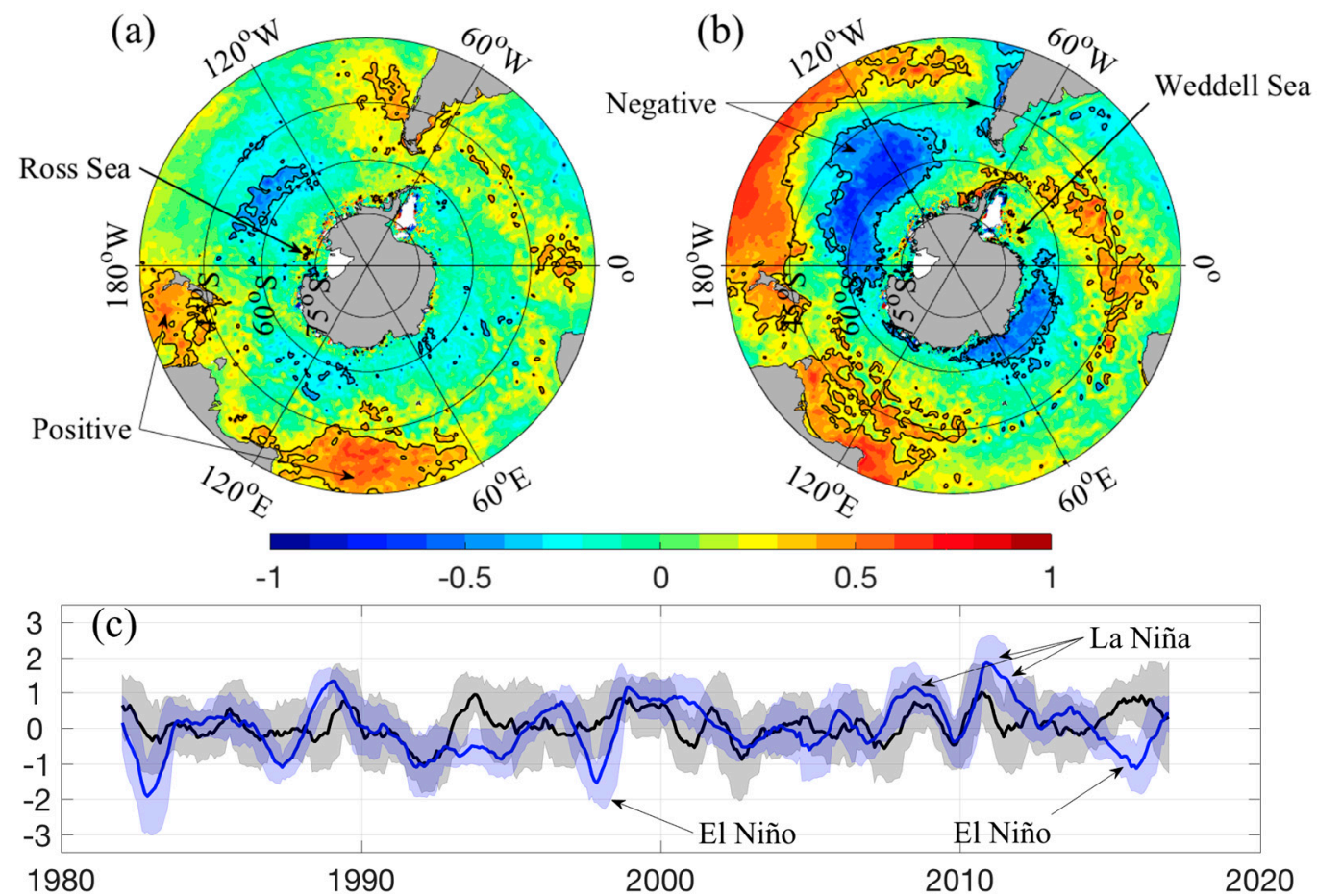

Figure 1. Pearson's correlation coefficient between standardized SST anomalies and the (a) Antarctic Oscillation (AAO) and (b) Southern Oscillation (SO). Negative (positive) coefficients are blue (red), and indicate decreased (increased) standardized SST anomalies. Coefficients interior to the black contour are significant (alpha $=0.05)$. (c) The 12-month running mean of AAO (black) and SO (blue) indices between 1982 and 2016, the shaded regions indicate the uncertainty.

During positive AAO years, the shift in the Westerlies correlates with anomalously warm surface waters in the mid-latitude Atlantic and Indian basins and a broad negative anomaly in the South Pacific (Figure 1a). A similar spatial pattern exists during positive SO years (Figure 1b). Positive SO years correlate with large-scale negative standardized SST anomalies in the high latitude Pacific and positive anomalies in the mid-latitude Pacific, along the west coast of Australia, and south of $45^{\circ} \mathrm{S}$ 
in the Atlantic. The spatial extent of significant SST anomaly correlations with the SO is larger than the correlations between SST and the AAO. Between the mid-2000's and 2014, both indices have been mostly in a positive phase (Figure 1c). When both indices are in the positive phase, spatial correlations relate increasing negative anomalies along the Antarctic coast with increasing positive anomalies in portions of the Ross and Weddell Seas and the sub-tropical Southern Ocean, similar to [24].

The influences of teleconnections are further explored through a more detailed analysis of the standardized SST anomalies (Figure 2). Spatial linear regressions from 1982 to 2016 in the Southern Ocean (Figure 2a) show significant large-scale surface warming (positive) in the mid-latitude Southern Ocean, the southern Indian Basin $\left(60^{\circ} \mathrm{E}-120^{\circ} \mathrm{E}\right)$, and the Amundsen Sea sector. In addition, significant negative trends in the South Pacific Basin and Drake Passage region are seen. An estimate of the Southern Ocean trends suggests a mean value of 0.0142 per year, a median of 0.0154 per year, and a distribution negatively skewed towards negative trends.
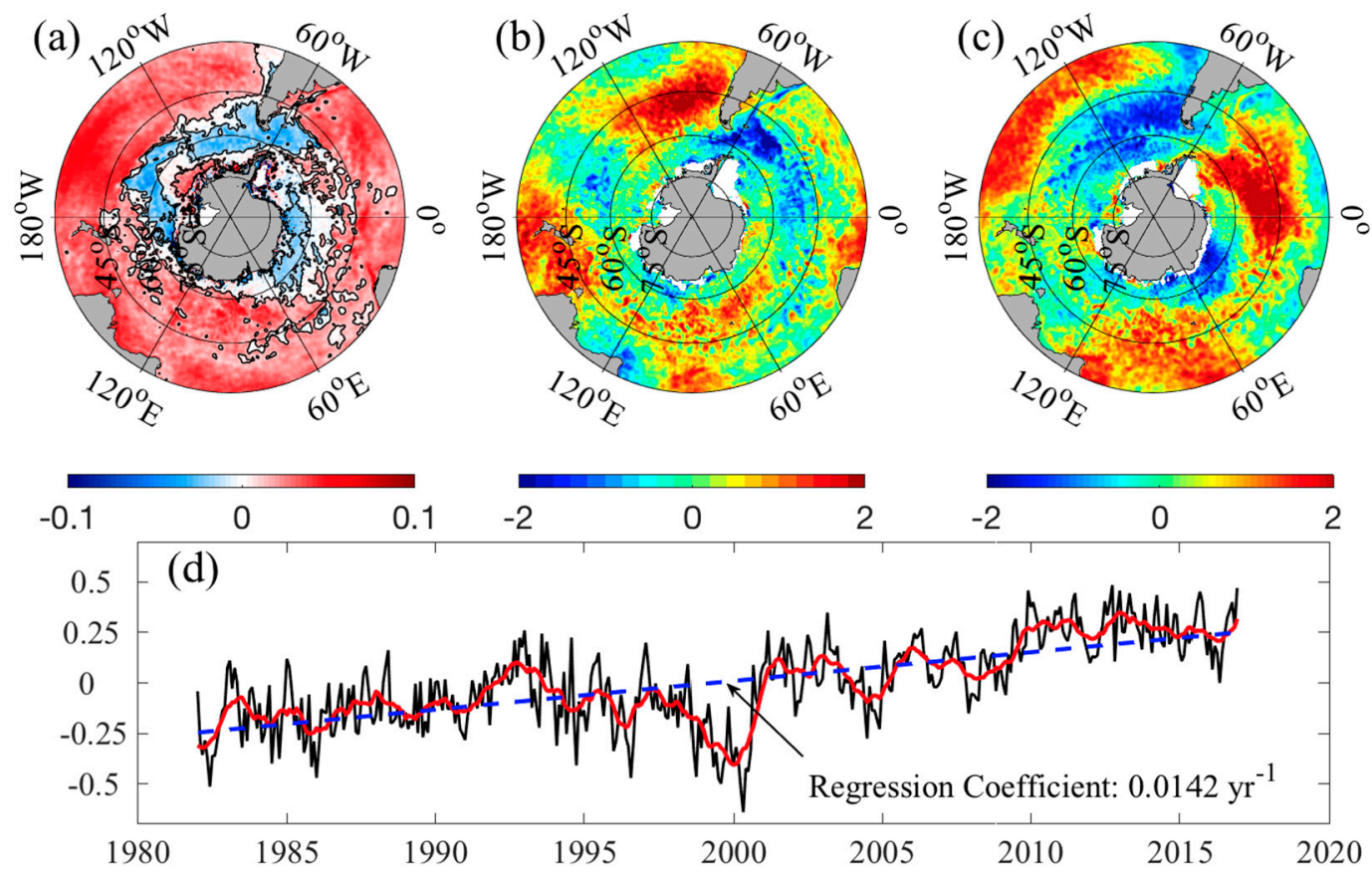

Figure 2. The 1982-2016 sea surface temperature (SST) coefficient of regression (year ${ }^{-1}$ ) (a), mean standardized SST anomalies during 2016 (b), and 2010 (c). In (a), values interior to black contour lines represent significant trends (alpha $=0.05)$. (d) The monthly averaged standardized SST anomalies (black) in the Southern Ocean ( $\left.30^{\circ} \mathrm{S}-70^{\circ} \mathrm{S}\right), 12$-month running mean (red), and the linear regression (dashed blue). The coefficient of regression is $0.0142 \mathrm{year}^{-1}$ and the coefficient of determination $\left(\mathrm{r}^{2}\right)$ is 0.436 . The temporal monthly standard error in regression is 0.0008 .

Comparing one-year averaged anomalies, we look to analyze two recent examples: a year with opposing index values and another with similar in-phase index values. In doing so, we explore the spatial regions and magnitudes of positive and opposing index years. Using Figure 1c, the years 2016 and 2010 were selected for each comparison respectively. The 2016 indices are described by a strong negative SO in the beginning of the year, changing to a strong positive SO by the end of the year with a consistently positive AAO (see Figure 1c). That is, the phases of the indices are mostly out of sync. The pattern of standardized SST anomalies (Figure 2b) from 2016 does show the strong similarities to the positive phases of both AAO and SO (i.e., negative sub-polar and positive sub-tropical anomalies), but also from the negative SO phase. The potency of the strong negative SO value (Figure $1 \mathrm{~b}$ ) is seen in the anomalously warm SSTs in the eastern and central sub-tropical Pacific Ocean (Figure 2b), both of which overshadow the values forced by the positive SO months. 
The 2010 mean standardized SST anomalies (Figure 2c) were the start of successive La Niña years (denoted in Figure 1c) and a positive AAO. Most notable are the anomalously warm temperatures in the sub-tropical Pacific, South Atlantic, and western Indian Basins. Moreover, there are strong negative anomalies in the South Pacific and in the South Indian Ocean (near 60 E). The pattern of 2010 positive and negative anomalies (Figure 2c) shares strong similarities with the positive and negative SST and SO correlations (Figure 1b), showing the strong influence of the in-phase oscillations on SST.

Temporal analysis of the mean Southern Ocean SST (Figure 2d) suggests warming at a rate of 0.0142 per year between 1982 and $2016\left(0.0092{ }^{\circ} \mathrm{C}\right.$ per year if not standardized), with a standard error of 0.0008 . The average was taken between $30^{\circ} \mathrm{S}$ and $70^{\circ} \mathrm{S}$ for each month. Throughout the 35 -year period, there was a net warming of approximately 0.50 based on standardized anomalies (approximately $0.32{ }^{\circ} \mathrm{C}$ if not standardized). A spatial comparison indicates that positive index months correlate to broad-scale warming in the mid-latitudes that supports the warming trend. To show the more recent relationship of in phases indices, Figure 3 depicts the standardized SST anomalies for AAO positive and SO neutral, AAO neutral and SO positive, and both AAO and SO positive indices. In this comparison, the opposing relationships of neutral-phase indices mitigate anomalies. However, during in-phase months of AAO and SO indices, the anomalies are greater in magnitude and broader spatially compared to either out-of-phase relationship, similar to the results of [29].

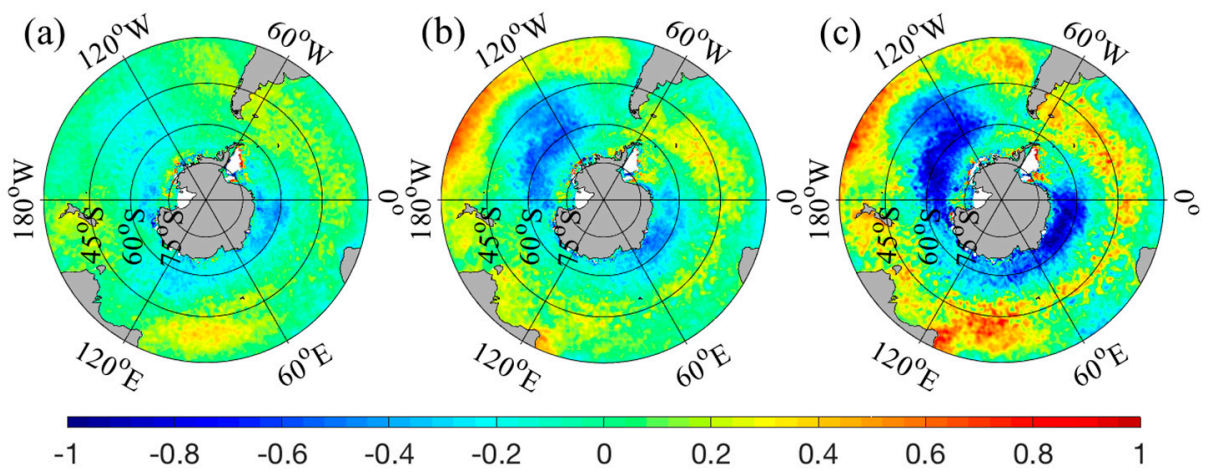

Figure 3. Monthly mean standardized sea surface temperature (SST) anomalies $\left({ }^{\circ} \mathrm{C}\right)$ during (a) positive Antarctic Oscillation (AAO) and neutral Southern Oscillation (SO) months, (b) neutral AAO and positive $\mathrm{SO}$ months, and (c) both positive $\mathrm{AAO}$ and $\mathrm{SO}$ months. In each instance, a positive (negative) index is defined as greater (less) than $0.5(-0.5)$ and neutral between -0.5 to 0.5 .

A comparison of monthly and yearly averaged standardized SST anomalies (Figure 4) mark contrasting differences between the temporal scales of AAO and the SO. The monthly (Figure 4a) and yearly (Figure 4b) averaged standardized SST anomalies during positive AAO events both have negative anomalies in the Pacific Basin and positive anomalies in the Atlantic and Indian Basins. On longer time-scales, this yearly pattern of anomalous temperatures is stronger than monthly averaged. Differences in the yearly and monthly AAO anomalies (Figure 4c) show the stronger (red) yearly signal, particularly east of the Greenwich Meridian and south of Australia to the dateline. Yearly anomalies are weaker (blue) in the high latitude Indian, the mid to high-latitude Atlantic and mid-latitude Central Pacific.

Although global air-sea interactions are heavily influenced by large-scale teleconnections, seasonal regressions derive a response in SST to changes in index values (Figure 5). In both instances, the largest coefficients of regression occur in austral summer and autumn, while the weakest coefficients arise in austral winter. Similar results for SST and ENSO were previously described in [27] and [29]. Based on these findings, spatial changes in austral summer indices can be used to depict linear changes in temperature. However, minimally significant regressions between austral winter anomalies and the indices suggest a potential non-linear or lag relationship. 

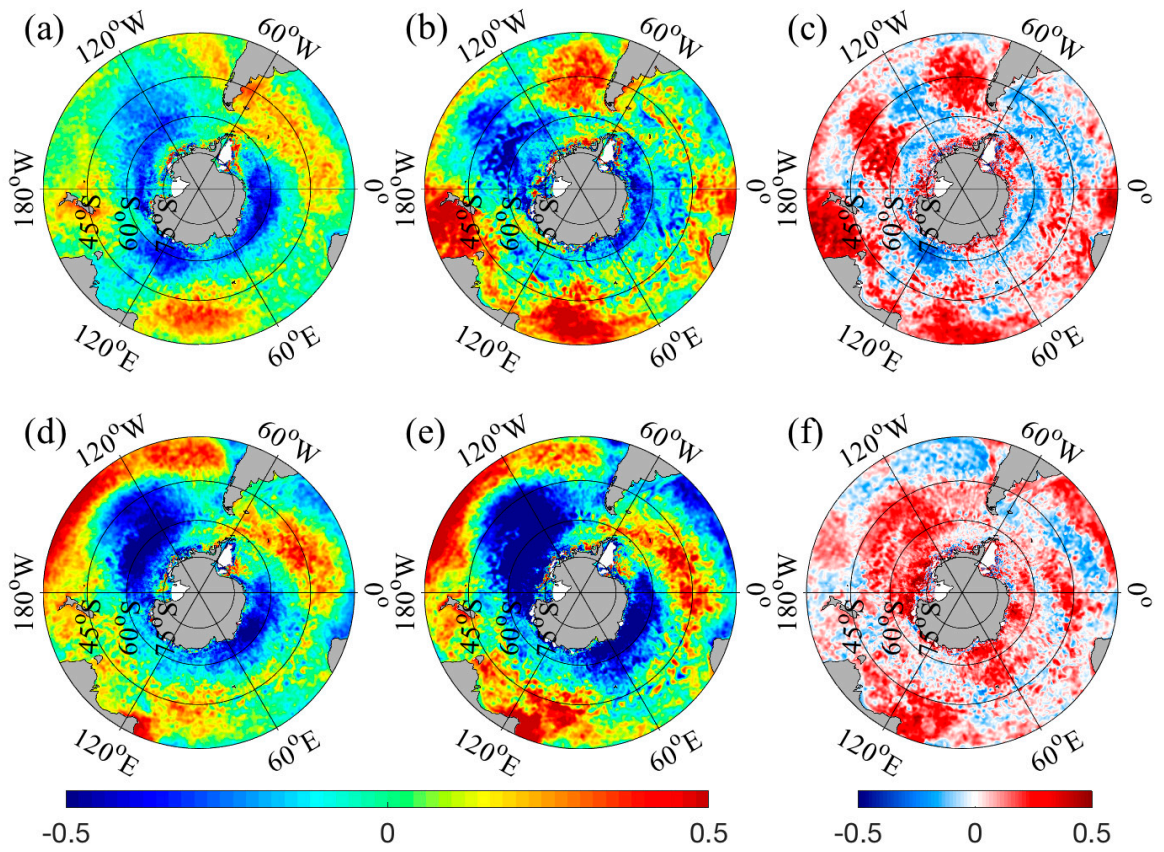

Figure 4. Monthly mean sea surface temperature (SST) standardized anomalies during positive Antarctic Oscillation (AAO) (a) and Southern Oscillation (SO) (d) months and (b,e) are standardized temperature anomalies during positive $\mathrm{AAO}$ and $\mathrm{SO}$ years respectively. $(\mathbf{c}, \mathbf{f})$ are the absolute value of yearly averaged anomalies minus the absolute value of monthly averaged anomalies. Red (blue) depicts yearly averages are greater (weaker) than monthly. In each instance, a positive index is defined as greater than 0.5 .

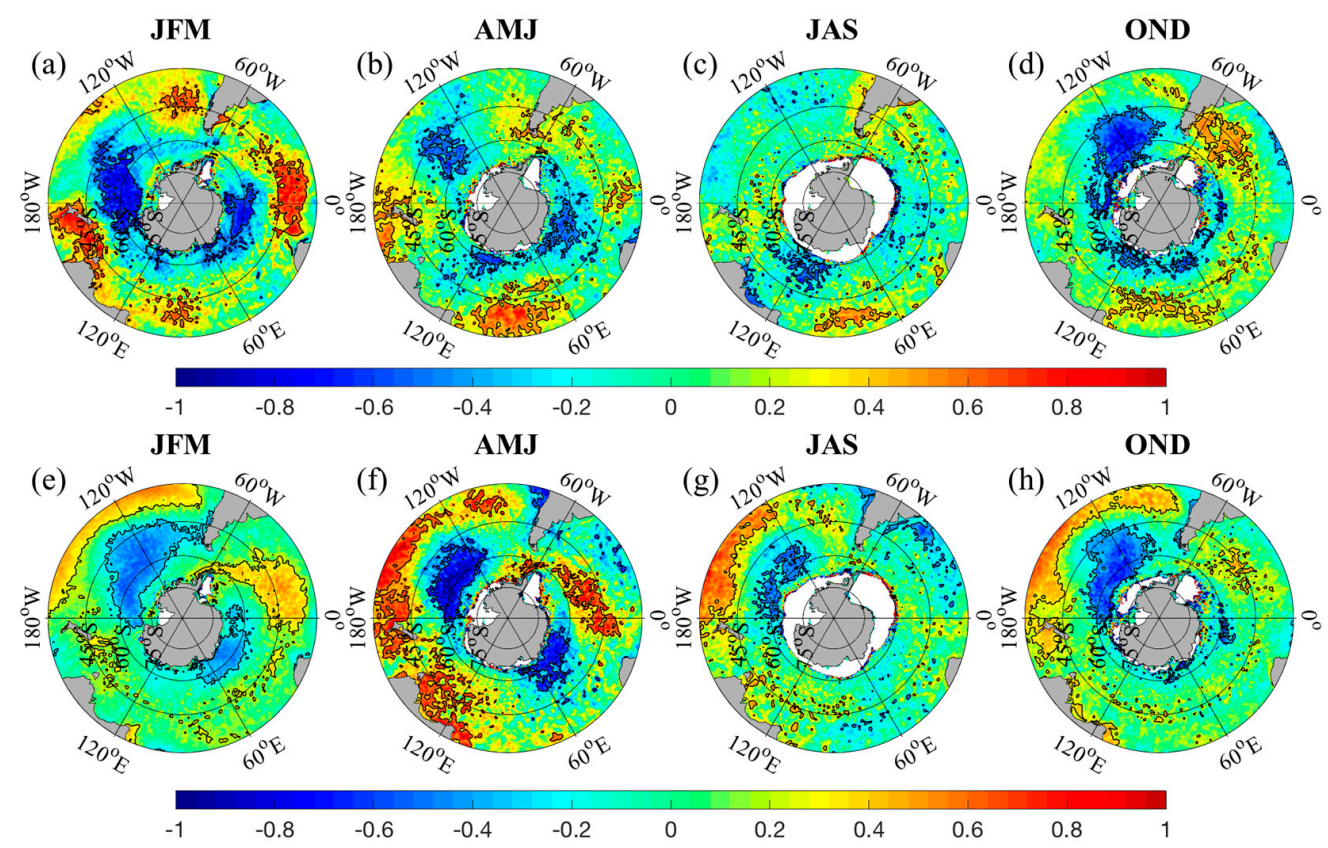

Figure 5. Coefficients of regression between the Southern Oscillation (AAO) (a-d) and standardized sea surface temperature (SST) anomalies $\left({ }^{\circ} \mathrm{C}\right.$ ) from 1982 to 2016. (a) is monthly anomalies averaged over January to March (austral summer), (b) April through June, (c) July through September (austral winter), and (d) October to December. The coefficients of regression between the SO (e-h) SST anomalies are through the same temporal scale as (a-d) respectively. The largest coefficients occur with AAO and SO during the austral summer and autumn, while the smallest coefficients occur in austral winter. 


\section{Discussion}

Analyzing correlations and mean standardized anomalies allow for the interpretation of how large-scale teleconnections influence the Southern Ocean. Strong positive indices of both the AAO and SO (La Niña) induce broad-scale cooling in the high latitudes of the Southern Ocean and warming in the mid-latitudes and Weddell Sea. Each index is seen to drive spatial anomalies on a magnitude of 0.5 and anomalies approaching 1 when both indices are in-phase. Within Figure 1a,b, the spatial correlations of the SO are more highly correlated spatially and based on magnitude, displaying the overlaying influence of the SO on the Southern Ocean SST. This result is important as the mid-2000's through 2012 were largely in-phase positive oscillations, associated with large-scale negative anomalies in the high latitudes and positive anomalies in the mid-latitudes and Weddell sea. More importantly, the spatial pattern in the temporal linear regression of SST is spatially similar to SST anomalies in 2010, a year marked by a strong La Niña period and a positive AAO index value, showing the importance of in-phase oscillations on SST. The continual positive indices within the 21st century would therefore be strongly contributing to the positive trend in Southern Ocean mid-latitude SST and negative trend within the Southern Hemisphere high latitudes.

The patterns of SST anomalies seen during positive SO monthly (Figure 4d) and yearly (Figure 4e) periods are similar, with intensification throughout the year in both the Indian and Pacific Basins (Figure 4f). This temporal disparity is most likely due to the time required for an Equatorial-Tropical Pacific phenomenon to influence large regions. A distinguishing feature of these patterns is that the magnitude of positive SO events in the Pacific Basin is greater than those associated with the AAO. The potential implication is that the SO plays a dominant role in the Southern Ocean. Furthermore, differences in yearly and monthly averaged anomalies are comparatively large. Thus, the longer duration of $\mathrm{AAO}$ and $\mathrm{SO}$ events could be an effective means of supporting or driving long-term trends.

SST anomalies can still be influenced by localized processes and feedback mechanisms. In years where the AAO and SO are increasingly positive, the Westerlies shift poleward and anomalously cooler temperatures are found in the high latitudes, with warmer temperatures in the mid-latitudes. There are breaks in the trend when strong El Niño events occur (negative SO), driving temperature changes that oppose the existing trend. Although this analysis supports the long-term increase in mean Southern Ocean surface temperature found by earlier analyses, it suggests that while the Atlantic and Indian Basins continue to warm, there has been significant cooling in the South Pacific as a result of the most recent patterns in the $\mathrm{AAO}$ and $\mathrm{SO}$.

\section{Conclusions}

In summary, an analysis of satellite-derived SST observations provides statistical grounds for measuring and understanding the spatial correlations between SSTs and global atmospheric teleconnection patterns. We find SSTs to be significantly correlated to both the AAO and the SO, with larger magnitude of anomalies associated with the $\mathrm{SO}$ events. Large-scale spatial patterns of both the AAO and the SO are significantly correlated to sea surface temperatures in Southern Ocean, driving significant cooling in Antarctic sub-polar regions and warming in the Southern Hemisphere subtropics. The recent in phase positive $\mathrm{AAO}$ and $\mathrm{SO}$ patterns are simultaneously driving significant cooling in the high latitude Pacific basin, despite broad-scale warming throughout the Southern Ocean at a rate of 0.0142 per year. We further find that the strong in phase austral summer and autumn relationships are driving the most significant changes. Our analysis, which suggests the potential for a continuous warming trend should the $\mathrm{AAO}$ and $\mathrm{SO}$ spend extended periods in their positive phases, provides strong grounds for the promotion of continued monitoring of the high latitude SST.

Acknowledgments: B.S.F. is supported by the NASA/South Carolina Space-grant Graduate Assistantship. NOAA's OISST v2 AVHRR data is obtained through the Earth Science Research Laboratory Physical Science Division (NOAA/ESRL/PSD) (https:/ / www.esrl.noaa.gov/psd/data/gridded/data.noaa.oisst.v2.highres.html). The indices for the Southern Oscillation and Antarctic Oscillation are distributed by the Climate Prediction 
Center (CPC) of the National Centers of Environmental Prediction (NCEP), National Oceanic and Atmospheric Administration (NOAA). A. Macdonald acknowledges support from NOAA Grant \#NA160AR4310172.

Author Contributions: B.S.F., B.S., and A.M.M. conceived and designed the data analysis and interpretation of the results. B.S.F. prepared all of the figures and prepared the manuscript and B.S. and A.M.M. guided this work and corrected the article.

Conflicts of Interest: The authors declare no conflict of interest. The founding sponsors had no role in the design of the study; in the collection, analyses, or interpretation of data; in the writing of the manuscript, and in the decision to publish the results.

\section{References}

1. Marshall, J.; Speer, K. Closure of the meridional overturning circulation through Southern Ocean upwelling. Nat. Geosci. 2012, 5, 171-180. [CrossRef]

2. Cheng, L.; Trenberth, K.E.; Fasullo, J.; Boyer, T.; Abraham, J.; Zhu, J. Improved estimates of ocean heat content from 1960 to 2015. Sci. Adv. 2017, 3, e1601545. [CrossRef] [PubMed]

3. Landschützer, P.; Gruber, N.; Haumann, F.A.; Rödenbeck, C.; Bakker, D.C.; Van Heuven, S.; Hoppema, M.; Metzl, N.; Sweeney, C.; Takahashi, T.; et al. The reinvigoration of the Southern Ocean carbon sink. Science 2015, 349, 1221-1224. [CrossRef] [PubMed]

4. Sarmiento, J.L.; Hughes, T.M.C.; Stouffer, R.J.; Manabe, S. Simulated response of the ocean carbon cycle to anthropogenic climate warming. Nature 1998, 393, 245-249. [CrossRef]

5. Gille, S.T. Warming of the Southern Ocean Since the 1950's. Science 2002, 295, 1275-1277. [CrossRef] [PubMed]

6. McNeil, B.I.; Matear, R.J. Southern Ocean Acidification: A Tipping Point at 450-ppm Atmospheric $\mathrm{CO}_{2}$. Proc. Natl. Acad. Sci. USA 2008, 105, 18860-18864. [CrossRef] [PubMed]

7. Montes-Hugo, M.; Doney, S.C.; Ducklow, H.W.; Fraser, W.; Martinson, D.; Stammerjohn, S.E.; Schofield, O. Recent Changes in Phytoplankton Communities Associated with Rapid Regional Climate Change Along the Western Antarctic Peninsula. Science 2009, 323, 1470-1473. [CrossRef] [PubMed]

8. Liu, J.; Curry, J.A. Accelerated Warming of the Southern Ocean and its Impacts on the Hydrological Cycle and Sea Ice. Proc. Natl. Acad. Sci. USA 2010, 107, 14987-14992. [CrossRef] [PubMed]

9. Dong, S.; Gille, S.T.; Sprintall, J. An Assessment of the Southern Ocean Mixed Layer Heat Budget. J. Clim. 2007, 20, 4425-4442. [CrossRef]

10. Downes, S.M.; Budnick, A.S.; Sarmiento, J.L.; Farneti, R. Impacts of wind stress on the Antarctic Circumpolar Current fronts and associated subduction. Geophys. Res. Lett. 2011, 38. [CrossRef]

11. Sun, C.; Watts, D.R. Heat flux carried by the Antarctic Circumpolar Current mean flow. J. Geophys. Res. 2002, 107. [CrossRef]

12. Dong, S.; Sprintall, J.; Gille, S.T. Location of the Antarctic polar front from AMSR-E satellite sea surface temperature measurements. J. Phys. Oceanogr. 2006, 36, 2075-2089. [CrossRef]

13. Gille, S.T. Meridional displacement of the Antarctic Circumpolar Current. Philos. Trans. R. Soc. A. 2014, 372, 20130273. [CrossRef] [PubMed]

14. Simmonds, I.; King, J.C. Global and hemispheric climate variations affecting the Southern Ocean. Antarct. Sci. 2004, 16, 401-413. [CrossRef]

15. Turner, J. The El Niño-Southern Oscillation and Antarctica. Int. J. Climatol. 2004, 24, 1-31. [CrossRef]

16. Hendon, H.H.; Lim, E.-P.; Nguyen, H. Seasonal variations of subtropical precipitation associated with the Southern Annular Mode. J. Clim. 2014, 27, 3446-3460. [CrossRef]

17. Hendon, H.H.; Thompson, D.W.J.; Wheeler, M. Australian rainfall and surface temperature variations associated with the Southern Hemisphere Annular Mode. J. Clim. 2006, 20, 2452-2467. [CrossRef]

18. Thompson, D.W.J.; Solomon, S. Interpretation of Recent Southern Hemisphere Climate Change. Science 2002, 296, 895-899. [CrossRef] [PubMed]

19. Thompson, D.W.J.; Solomon, S.; Kushner, P.J.; England, M.H.; Grise, K.M.; Karoly, D.J. Signatures of the Antarctic ozone hole in Southern Hemisphere surface climate change. Nat. Geosci. 2001, 4, 741-749. [CrossRef]

20. Gille, S.T. Yearly-Scale Temperature Trends in the Southern Hemisphere Ocean. J. Clim. 2008, 21, 4749-4765. [CrossRef] 
21. Durack, P.J.; Wijffels, S.E. Fifty-year trends in global ocean salinities and their relationship to broad-scale warming. J. Clim. 2010, 23, 4342-4362. [CrossRef]

22. Böning, C.W.; Dispert, A.; Visbeck, M.; Rintoul, S.R.; Schwarzkopf, F.U. The response of the Antarctic Circumpolar Current to recent climate change. Nat. Geosci. 2008, 1, 864-869. [CrossRef]

23. Ciasto, L.M.; Thompson, D.W. Observations of large-scale ocean-atmosphere interaction in the Southern Hemisphere. J. Clim. 2008, 21, 1244-1259. [CrossRef]

24. Ciasto, L.M.; Alexander, M.A.; Deser, C.; England, M.H. On the persistence of cold-season SST anomalies associated with the Annular Mode. J. Clim. 2011, 24, 2500-2515. [CrossRef]

25. Xiao, B.; Zhang, Y.; Yang, X.Q.; Nie, Y. On the role of extratropical air-sea interaction in the persistence of the Southern Annular Mode. Geophys. Res. Lett. 2016, 43, 8806-8814. [CrossRef]

26. Mo, K.C. Relationships between low-frequency variability in the Southern Hemisphere and sea surface temperature anomalies. J. Clim. 2000, 13, 3599-3610. [CrossRef]

27. Welhouse, L.J.; Lazzara, M.A.; Keller, L.M.; Tripoli, G.J.; Hitchman, M.H. Composite analysis of the effects of ENSO events on Antarctica. J. Clim. 2016, 29, 1797-1808. [CrossRef]

28. Cerrone, D.; Fusco, G.; Simmonds, I.; Aulicino, G.; Budillon, G. Dominant Covarying Climate Signals in the Southern Ocean and Antarctic Sea Ice Influence during the Last Three Decades. J. Clim. 2017, 30, 3055-3072. [CrossRef]

29. Fogt, R.L.; Bromwich, D.H. Decadal variability of the ENSO teleconnection to the high-latitude South Pacific governed by coupling with the southern annular mode. J. Clim. 2006, 19, 979-997. [CrossRef]

30. Lyman, J.M.; Johnson, G.C. Estimating annual global upper-ocean heat content anomalies despite irregular in situ ocean sampling. J. Clim. 2008, 21, 5629-5641. [CrossRef]

31. Talley, L.D.; Feely, R.A.; Sloyan, B.M.; Wanninkhof, R.; Baringer, M.O.; Bullister, J.L.; Carlson, C.A.; Doney, S.C.; Fine, R.A.; Firing, E.; et al. Changes in Ocean Heat, Carbon Content, and Ventilation: A Review of the First Decade of GO-SHIP Global Repeat Hydrography. Annu. Rev. Mar. Sci. 2016, 8, 185-215. [CrossRef] [PubMed]

32. Reynolds, R.W.; Smith, T.M.; Liu, C.; Chelton, D.B.; Casey, K.S.; Schlax, M.G. Daily High-Resolution-Blended analyses for sea surface temperature. J. Clim. 2007, 20, 5473-5496. [CrossRef]

33. Kalnay, E.; Kanamitsu, M.; Kistler, R.; Collins, W.; Deaven, D.; Gandin, L.; Iredell, M.; Saha, S.; White, G.; Woollen, J.; et al. The NCEP/NCAR 40-Year Reanalysis Project. Bull. Am. Meteorol. Soc. 1996, 77, 437-471. [CrossRef]

34. Trenberth, K.E.; Caron, J.M. The Southern Oscillation revisited: Sea level pressures, surface temperatures, and precipitation. J. Clim. 2000, 13, 4358-4365. [CrossRef] 